\title{
Influence of sorbitol on mechanical and physico-chemical properties of soy protein-based bioplastics processed by injection molding
}

\author{
Manuel Felix ${ }^{1 *}$, Valme Carpintero ${ }^{1}$, Alberto Romero ${ }^{1}$ and Antonio Guerrero ${ }^{1}$ \\ ${ }^{1}$ Department of Chemical Engineering, Faculty of Chemistry, University of Seville, Seville, Spain \\ *mfelix@us.es
}

\begin{abstract}
Soy Protein Isolate (SPI) has been evaluated as useful candidate for the development of protein-based bioplastic materials processed by injection molding. The influence of sorbitol (SB) as plasticizer in mechanical properties and water uptake capacity was evaluated in SPI-based bioplastics. A mixing rheometer that allows monitoring torque and temperature during mixing and a small-scale-plunger-type injection molding machine were used to obtain SPI/Plasticizer blends and SPI-based bioplastics, respectively. Dynamic measurements were carried out to obtain mechanical spectra of different bioplastics. Moreover, the mechanical characterization was supplemented with uniaxial tensile tests. Additionally, the influence of SB in water uptake capacity was also evaluated. The introduction of SB leads to increase the rigidity of bioplastics as well as the water uptake capacity after $24 \mathrm{~h}$, however it involves a decrease in strain at break. Final bioplastics are plastic materials with both adequate properties for the substitution of conventional petroleum plastics and high biodegradability.
\end{abstract}

Keywords: bioplastics, DMTA, plasticizer, sorbitol, soy protein.

\section{Introduction}

The use of petroleum-based materials involves serious environmental damage. Each year, over 300 million tons of petroleum-based or gas-based polymers are produced worldwide for a wide variety of applications in almost all areas of daily life as well as in the process industry ${ }^{[1,2]}$. However, recently concerns about the decrease in new fossil resources, together with the lack of biodegradability of plastic materials, have encouraged the replacement of conventional oil-based plastics by others based on hydrocarbons derived from renewable resources ${ }^{[3,4]}$. Proteins are one the most promising renewable source for obtaining bio-based materials. These tend to form three-dimensional macromolecular networks, which are stabilized by hydrogen bonds, hydrophobic interactions, and disulfide bonds ${ }^{[5]}$. The diversity in protein availability, as well as in their assembling, a big amount of biodegradable materials can be obtained, offering a wide range of techno-functional properties ${ }^{[6]}$.

Protein-based bioplastics can be processed by using existing processing technologies, from the physicochemica ${ }^{[7]}$ to thermomechanical methods (compression molding, thermomolding and extrusion $)^{[8]}$. However, injection molding, which is the most common processing method used with synthetic polymers, has been poorly used for protein-based bioplastic applications ${ }^{[9]}$. This technique would suffer a remarkable demand if the feasibility of performing protein-based materials were demonstrated. The use of injection-molding technique to produce protein-based bioplastics enable the manufacture of many kinds of shaped products, which entails new arguments in favor of considering these biodegradable polymers as an alternative to synthetic polymers. This technique has

been previously used for the elaboration of crayfish-based bioplastics $^{[10]}$, pea-based bioplastics ${ }^{[11]}$, albumen-based ${ }^{[8]}$ bioplastics or soy-based bioplastics ${ }^{[12]}$, among others. However, glycerol has been used as the only plasticizer in these works and sorbitol has not previously tested. Before injecting the protein into the mould, it is necessary to obtain a protein/plasticizer blends ${ }^{[13]}$. Proteins themselves do not have sufficient plasticity to be handled, for this reason a plasticiser is required. The plasticiser reduces intermolecular forces and increase polymeric chains mobility ${ }^{[7]}$. Moreover, the plasticiser reduces the glass transition temperature of the thermoplastic proteins ${ }^{[14]}$. The most common plasticisers include water and polyols. Some of the most used plasticizer are the glycerol (GL) and the sorbitol (SB). These hydrophilic compounds have been used, among other biopolymers, in starch films ${ }^{[5,13,15]}$ in order to improve their mechanical and barrier properties.

The overall objective of this work was to evaluate the feasibility of using SB for developing high quality biodegradable soy-protein bio-based plastic materials (bioplastics) processed by injection molding with desirable thermo-mechanical properties and high biodegradability. To achieve this objective, soy protein concentrate (SPI) was processed with GL and SB (dissolved in glycerol or water). The mixing process was monitored using a mixing rheometer that allows the torque and temperature to be recorded during mixing. Mechanical properties of the final bioplastic materials were obtained by means of dynamic measurements (DMTA) and tensile-strength tests. Finally, the water uptake capacity, the loss of soluble matter and the swelling were determined. 


\section{Materials and Methods}

\subsection{Materials}

Soy protein isolate (SPI) was supplied by Protein Technologies International (Leper, Belgium). The protein content was $91.0 \pm 0.2 \mathrm{wt}$ \%. Both plasticizers, glycerol (GL) and sorbitol (SB), were purchased from Panreac Química, S.A. (Spain).

\subsection{Sample preparation}

Blends with constant protein/plasticizer ratio were manufactured by a thermomechanical procedure which includes two stages: Initially, blends were mixed in a two-blade counter-rotating batch mixer Haake Polylab QC (ThermoHaake, Germany) at $25^{\circ} \mathrm{C}$ and 50 r.p.m. for 10 min., monitoring torque and temperature. The protein/plasticizer ratios selected were $50 \mathrm{wt} . \%$ and $50 \mathrm{wt}$ \% concentration for the protein and plasticizer, respectively (denoted as $50 / 50$ ), and this ratio was kept constant in any case. Initially, the GL was used as the plasticizer of reference. After that, the influence of the SB as a plasticizer was evaluated (maintaining constant protein/plasticizer ratio). One of the most obvious constraints was the use of a solid plasticizer (SB). Initially, SB was mixed directly with the protein powder, however the blend was not suitable for the injection due to its lack of processability. For this reason, the SB was introduced dissolved in either GL or water (W) at the saturation concentration (50 and $70 \mathrm{wt} . \%$, respectively). This SB saturated solution was used as plasticizer, and was introduced in a ratio of 50/50 (SPI/plasticizer). The specific mechanic energy (SME) of mixing (Equation 1) may be defined as follows ${ }^{[16]}$ :

$$
S M E=\frac{\omega}{m} \int_{0}^{t_{m i x}} M(t) d t
$$

where $\omega$ (in $\mathrm{rad} / \mathrm{s}$ ) is the mixing speed, $\mathrm{m}$ (in $\mathrm{g}$ ) is the sample mass, $M(t)$ (in $N \cdot m$ ) is the torque and $t_{\text {mix }}$ (in s) is the mixing time.

Secondly, the dough-like materials selected after mixing process were processed by injection molding using a MiniJet Piston Injection Molding System II (ThermoHaake, Germany) to obtain bioplastic specimen, the injection conditions were: cylinder temperature: $40{ }^{\circ} \mathrm{C}$, mold temperature: $70{ }^{\circ} \mathrm{C}$, injection pressure: $500 \mathrm{bar}(20 \mathrm{~s})$ and post-injection pressure: $200 \mathrm{bar}(200 \mathrm{~s})^{[14]}$. Two types of molds were used: a $60 \times 10 \times 1 \mathrm{~mm}$ rectangular shape mold for both DMTA experiments and water uptake, and a Dumpbell type probe defined by ISO 527-2 $2^{[15]}$ for Tensile Properties.

\subsection{Characterization of biocomposites}

\subsubsection{Dynamic Mechanical Temperature Analysis (DMTA)}

DMTA tests were carried out with a RSA3 (TA Instruments, New Castle, DE, USA), on rectangular specimens using dual cantilever bending. All the experiments were carried out at constant frequency $(1 \mathrm{~Hz}$ ) and strain (between 0.01 and $0.30 \%$, within the linear viscoelastic region). The selected heating rate was $3{ }^{\circ} \mathrm{C} \cdot \mathrm{min}^{-1}$ and the temperature interval was from -10 to $75^{\circ} \mathrm{C}$.

\subsubsection{Tensile-strength measurements}

Tensile-strength tests were performed by using the Insight $10 \mathrm{kN}$ Electromechanical Testing System (MTS, Eden Prairie, MN, USA), according to by ISO 527-2 $2^{[17]}$ for Tensile Properties of Plastics. Young's Modulus (E), maximum stress $\left(\sigma_{\max }\right)$ and strain at break $\left(\varepsilon_{\max }\right)$ were evaluated from at least five duplicates for each product using type IV probes and an extensional rate of $1 \mathrm{~mm} \cdot \mathrm{min}^{-1}$.

\subsubsection{Water uptake capacity}

Water uptake capacity of bioplastics were measured according to the standard ASTM D-570 ${ }^{[18]}$. The specimens were subjected to drying (conditioning) in an oven at $50 \pm 2^{\circ} \mathrm{C}$ for 5-6 hours to determine dry weight, then introduced into distilled water and weighed at 2 and 24 hours of immersion. Finally, it is subjected to drying (reconditioning) again and weighed to determine the loss of soluble material. All the experiments were performed in triplicate at room temperature. Water absorption capacity and loss of soluble material are determined by the following equations:

$$
\% \text { Water uptake }=\frac{\text { Wet Weight }- \text { Initial Dry Weight }}{\text { Initial Dry Weight }} \cdot 100
$$

$$
\begin{aligned}
& \% \text { Loss of } \\
& \text { soluble material }
\end{aligned}=\frac{\text { Initial Dry weight }- \text { Final Dry weight }}{\text { Initial Dry weight }} \cdot 100
$$

The swelling capacity was carried out as follows: the thickness of the rectangular probes was measured before the water immersion. After $24 \mathrm{~h}$, probes were carefully dried and their thickness was again measured. The swelling ratios of the SPI-based bioplastics were obtained by the following equation.

$$
\% \text { swelling }=\frac{\text { Initial thikcness }- \text { Final thikcness }}{\text { Initial } \text { thickness }} \cdot 100
$$

\subsection{Statistical analysis}

At least three replicates of each measurement were carried out. Statistical analyses were performed using t-test and one-way analysis of variance (ANOVA, $\mathrm{p}<0.05$ ). Standard deviations were calculated.

\section{Results and Discussions}

\subsection{Preparation of blends by thermoplastic mixing}

Figure 1 shows torque and temperature profiles as a function of mixing time for different blends. These results indicate the relevant dependence of torque and temperature on the plasticizer used. Thus, all profiles are characterized by a rapid increase in torque up to reach a maximum value (specially marked for SPI/GL system), followed by a decrease which is asymptotical towards a plateau value for SPI/GL and SPI/W/SB, and is subsequently followed by a moderate increase (reaching a value plateau) in SPI/GL/SB system. Temperature profiles are characterized by an almost constant value around $25^{\circ} \mathrm{C}$ for SPI/GL and SPI/W/GL systems and by a moderate increase in the SPI/GL/SB system. The temperature profiles are in accordance with torque profiles, constant 
torque values at middle-time lead to constant temperature profiles. Moreover, the increase in torque is a consequence of the shear-induced crosslinking events which take place over the mixing stage of SPI/GL/SB system.

As a consequence of the above-mentioned differences in torque profile, the energy employed for mixing (SME) is also quite different. The values for the SME for these three systems are included in Figure 1. A remarkable increase in this parameter can be observed in the SPI/W/SB system. This effect is related to the increase in torque caused by a structuration of the system, which leads to decrease the processability of blends.

\subsection{Mechanical characterization of bioplastics}

\subsubsection{Dynamic Mechanical Temperature Analysis (DMTA)}

Figure 2 shows the values of the storage modulus (E'), the loss modulus (E") (Figure 2A) and the loss tangent, tan $\delta$ (Figure 2B), as a function of temperature, obtained from DMTA measurements for different plasticizer.

As may be observed in Figure 2A, all the specimens show similar profiles for E' and for E", undergoing a

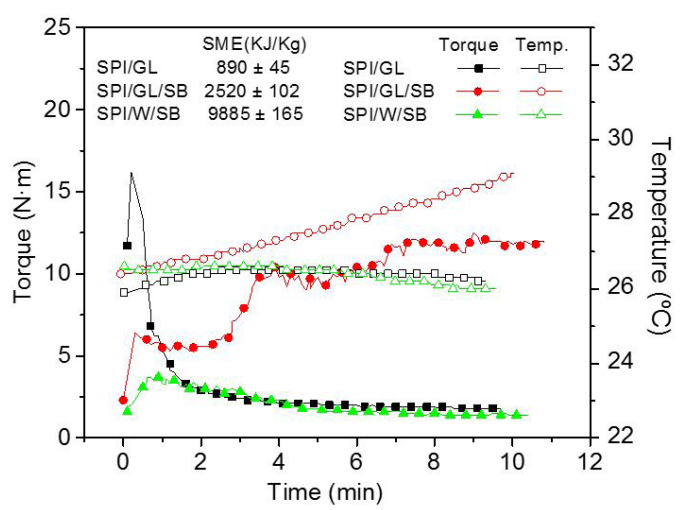

Figure 1. Evolution of mixing torque and temperature as a function of time for systems SPI/GL, SPI/GL/SB and SPI/W/SB, as well as SME for all the protein-plasticizer studied (table inset). remarkable decrease with increasing temperature. The higher structuration found in SPI/W/SB blends, is also found for probes at this protein/plasticizer composition. This system yields probes with higher viscoelastic modulus (E' and E"), which indicates the higher protein-network formation during the injection molding stage. In any case, the use of SB as plasticizer seems to favor the protein-crosslinking of the final probes, which is factually the probe containing SB dissolved in water. The higher moduli found can be related to the fact that some of the water is lost during the injection stage, increasing the rigidity of the final probes.

All the probes studied display similar loss tangent profiles (Figure 2B), which is characterized by an almost constant increase towards a maximum value. This behavior has been previously related to a glass-like transition ${ }^{[9]}$. The unimodal profiles indicate a good compatibility, between protein isolate and the different plasticizers, for all the systems after the injection molding process, regardless of the plasticizer used (GL, GL/SB or W/SB). Tan $\delta$ values are always lower than 0.5 , which indicates the marked solid character of all systems studied, however the increase in temperature leads to increase the $\tan \delta$ in any case, indicating that the solid character of probes is reduced.

\subsubsection{Uniaxial tensile-strength measurements}

Figure $3 \mathrm{~A}$ displays the stress-strain curves obtained from tensile-strength measurements for all systems studied containing different plasticizers. The mechanical responses consist of an initial linear elastic interval, characterized by a constant stress-strain slope, which yields high values for the Young's Modulus (E), followed by a deformation stage with a continuous decrease in the stress-strain slope. A second constant slope is reached over the plastic deformation stage. Before the end, all the curves reach a maximum value for the stress $\left(\sigma_{\max }\right)$, followed by a decrease in $\sigma$ and the strain at break $\left(\varepsilon_{\max }\right)$ is reached. Probes containing GL seems to lead higher $\varepsilon_{\max }$, however probes containing SB have higher initial slope, which denotes higher elastic modulus. In order to carry out a proper comparison of all parameters from stress-strain curves, the values of these parameters $\left(\mathrm{E}, \sigma_{\max }\right.$ and $\left.\varepsilon_{\max }\right)$ and their corresponding standard deviations

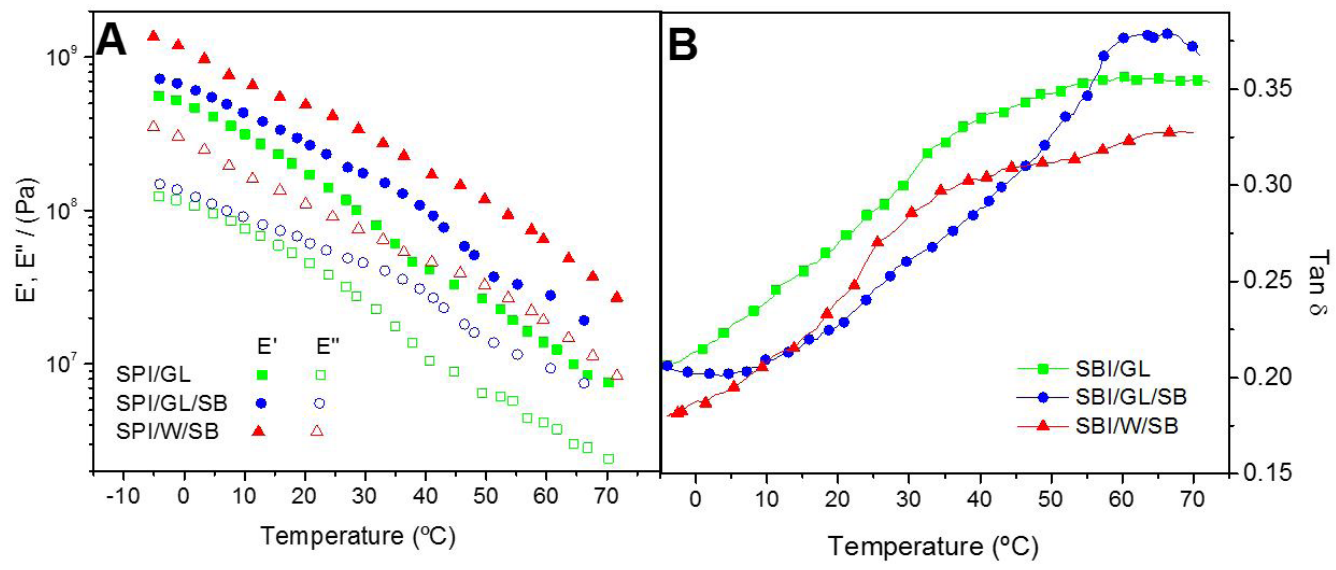

Figure 2. DMTA temperature ramp measurements, at $1 \mathrm{~Hz}$ and $3{ }^{\circ} \mathrm{C} \cdot \mathrm{min}^{-1}$, all the studied systems $(\mathrm{SPI} / \mathrm{GL}, \mathrm{SPI} / \mathrm{GL} / \mathrm{SB}$ and $\mathrm{SPI} / \mathrm{W} / \mathrm{SB})$ : (A) storage modulus ( $\left.\mathrm{E}^{\prime}\right)$ and $(\mathrm{B}) \tan \delta$. 

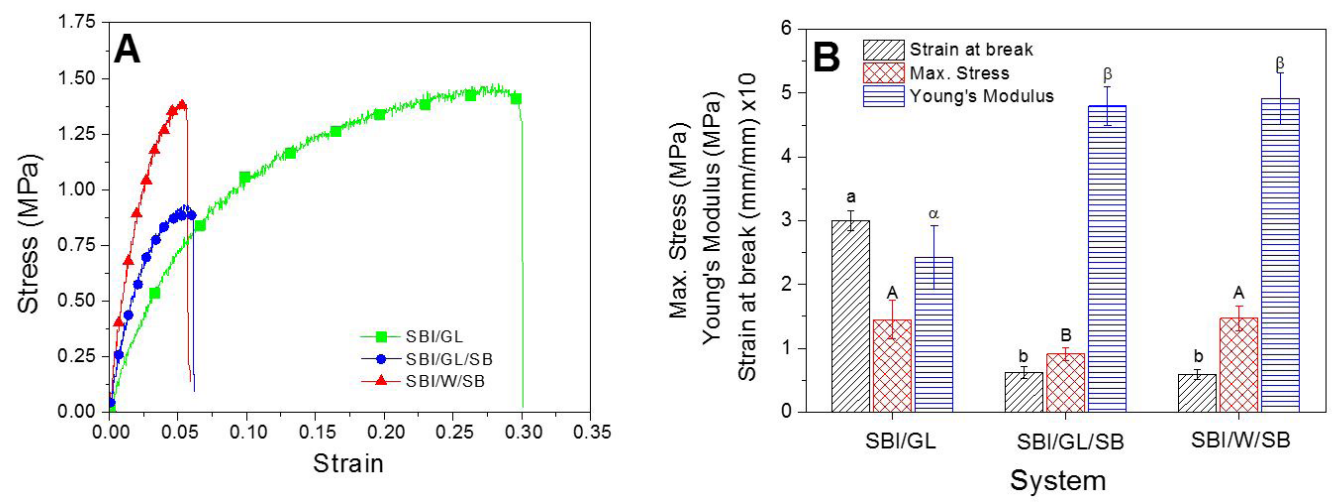

Figure 3. Stress-Strain curves from tensile strength measurements (A) and parameters from tensile strength measurements: Maximum stress $\left(\sigma_{\max }\right)$, strain at break $\left(\varepsilon_{\max }\right)$ and Youngs' Modulus (E) for the different probes studied (SPI/GL, SPI/GL/SB and SPI/W/SB) (B).

are plotted in Figure 3B for all the systems studied. This figure puts forward that the probe in which the GL is the only plasticizer, is the one that exhibits the highest $\varepsilon_{\max }$. On the contrary, SB-containing probes exhibit higher Young`s Modulus (elastic response), regardless of the plasticizer in which the SB is dissolved (GL or W). These results evidence the SB decreases the sliding ability of the different protein chains when the SB plays the role of plasticizer. Moreover, SPI-based probes do not experiment a noticeable decrease in $\sigma_{\max }$ when after adding SB an increase in $\mathrm{E}$ takes place. Interestingly, this mechanical response is different to that one previously found by Felix et al. ${ }^{[10,19]}$ and Rombouts et al. ${ }^{[20]}$, however are in consonance with the mechanical properties found by Schmid et al. ${ }^{[21]}$ and Tummala et al. ${ }^{[22]}$ In any case, these elastic responses are consistent with the results from DMTA that showed lower elastic modulus (E') for the system without SB (Figure 2A). These results indicate the feasibility of modulating mechanical properties of bioplastics where mechanical properties obtained after changing the plasticizer used are suitable for different applications.

\subsection{Water uptake capacity}

Figure 4 shows the results from water uptake measurements. As it may be observed, all probes have a remarkable a high water uptake ability, which is related to the abundance of hydrophilic group in the SPI system. In fact, the value reached is much higher than those previously reported for albumen-based bioplastics or soy ${ }^{[9,12]}$. The use of SB as plasticizer seems to give raises an increase in water uptake after $24 \mathrm{~h}$, which is probably related to the high hydrophilicity of this solid sugar alcohol. As regards the water-soluble loss matter the systems studied show a value of around $40 \%$. These results suggest that the loss of soluble matter corresponds basically to the hydrophilic character of GL and W (liquid plasticizer used), which are easily release into the medium. These results are similar to other previously obtained, and also were attributed to the loss of plasticizer ${ }^{[9,11]}$. Finally, the swelling ratio is very similar for the systems containing GL, regardless of the presence of SB. However, when the SB is dissolved in W, the measurement of the swelling is impossible, because the probe is very irregular after the immersion in water for $24 \mathrm{~h}$.

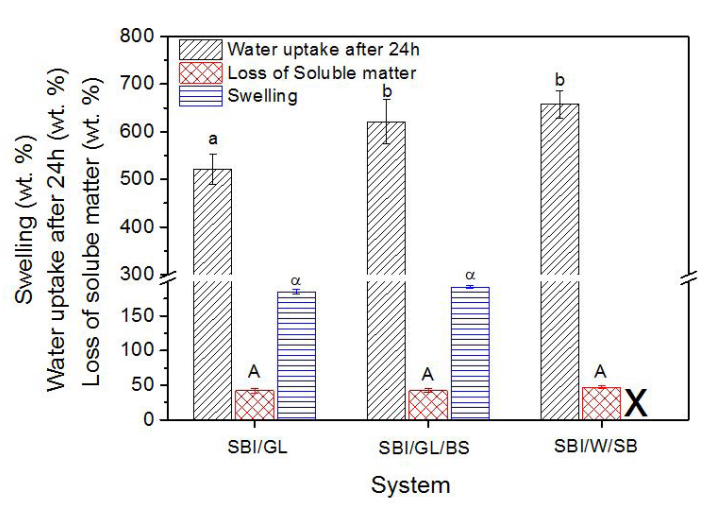

Figure 4. Evolution of water uptake capacity (\%) after immersion for $24 \mathrm{~h}$ in water, loss of soluble matter (\%), and swelling for all the studied systems (SPI/GL, SPI/GL/SB and SPI/W/SB).

\section{Conclusions}

The use of SB as plasticizer gives rise SPI- based bioplastics with different mechanical properties, which can be suitable for their use in different applications. All probes exhibit similar DMTA profiles, which are characterized by a decrease in both moduli (E' and E'), however, the sorbitol seems to yield probes more rigid (higher values of E' and E). This higher elastic response is also observed in tensile-strength measurements. In addition, the change of plasticizer allows the manufacturing of probes with different mechanical properties (both the $\sigma_{\max }$ and $\varepsilon_{\max }$ can be modulated). Results from water uptake capacity reveal a remarkable capacity of these SPI-based probes to absorb water, which is much higher than that one found for other protein-based bioplastics. The use of sorbitol increases this ability, which can contribute to obtain highly-demanded new super-absorbent materials.

\section{Acknowledgements}

This work is part of a research project sponsored by Andalousian Government, (Spain) (project TEP-6134) and by "Ministerio de Economía y Competitividad" from Spanish Government (Ref. CTQ2015-71164-P). 


\section{References}

1. DiGregorio, B. E. (2009). Biobased performance bioplastic: mirel. Chemistry \& Biology, 16(1), 1-2. PMid:19171300. http:// dx.doi.org/10.1016/j.chembiol.2009.01.001.

2. Rocha, G. O., Farias, M. G., Carvalho, C. W. P., Ascheri, J. L. R., \& Galdeano, M. C. (2014). Biodegradable composite films based on cassava starch and soy protein. Polimeros: Ciência e Tecnologia, 24(5), 587-595. http://dx.doi.org/10.1590/01041428.1355 .

3. Thiré, R. M. S. M., Simao, R. A., Araújo, P. J. G., Achete, C. A., \& Andrade, C. T. (2004). Reduction of hydrophilicity of biodegradable starch-based films by plasma polymerization. Polímeros: Ciência e Tecnologia, 14(1), 57-62. http://dx.doi. org/10.1590/S0104-14282004000100015.

4. Macea, R. B., De Hoyos, C. F., Montes, Y. G., Fuentes, E. M., \& Ruiz, J. I. R. (2015). Synthesis and film properties of chitosan and whey. Polimeros: Ciência e Tecnologia, 25(1), 58-69. http://dx.doi.org/10.1590/0104-1428.1558.

5. Winkworth-Smith, C., \& Foster, T. J. (2013). General overview of biopolymers: structure, properties, and applications. In S. Thomas, D. Durand, C. Chassenieux \& P. Jyotishkumar (Eds.). Handbook of biopolymeric materials. Weinheim: Wiley-VCH Verlag GmbH \& Co. KGaA. http://dx.doi. org/10.1002/9783527652457.ch2.

6. Verbeek, C. J. R., \& van den Berg, L. E. (2010). Extrusion Processing and Properties of Protein-Based Thermoplastics. Macromolecular Materials and Engineering, 295(1), 10-21. http://dx.doi.org/10.1002/mame.200900167.

7. Genadios, A. (2002). Proteins based films and coting. New York: CRC Press. http://dx.doi.org/10.1201/9781420031980.

8. Jerez, A., Partal, P., Martinez, I., Gallegos, C., \& Guerrero, A. (2005). Rheology and processing of gluten based bioplastics. Biochemical Engineering Journal, 26(3), 131-138. http://dx.doi. org/10.1016/j.bej.2005.04.010.

9. Felix, M., Martin-Alfonso, J. E., Romero, A., \& Guerrero, A. (2014). Development of albumen/soy biobased plastic materials processed by injection molding. Journal of Food Engineering, 125, 7-16. http://dx.doi.org/10.1016/j.jfoodeng.2013.10.018.

10. Felix, M., Romero, A., Cordobes, F., \& Guerrero, A. (2015). Development of crayfish bio-based plastic materials processed by small-scale injection moulding. Journal of the Science of Food and Agriculture, 95(4), 679-687. PMid:24909425. http:// dx.doi.org/10.1002/jsfa.6747.

11. Perez, V., Felix, M., Romero, A., \& Guerrero, A. (2016). Characterization of pea protein-based bioplastics processed by injection moulding. Food and Bioproducts Processing, 97, 100-108. http://dx.doi.org/10.1016/j.fbp.2015.12.004.

12. Fernández-Espada, L., Bengoechea, C., Cordobés, F., \& Guerrero, A. (2016). Protein/glycerol blends and injectionmolded bioplastic matrices: Soybean versus egg albumen. Journal of Applied Polymer Science, 133(6), n/a. http://dx.doi. org/10.1002/app.42980.
13. Suyatma, N. E., Tighzert, L., Copinet, A., \& Coma, V. (2005). Effects of Hydrophilic Plasticizers on Mechanical, Thermal, and Surface Properties of Chitosan Films. Journal of Agricultural and Food Chemistry, 53(10), 3950-3957. PMid:15884822. http://dx.doi.org/10.1021/jf048790+.

14. Irissin-Mangata, J., Bauduin, G., Boutevin, B., \& Gontard, N. (2001). New plasticizers for wheat gluten films. European Polymer Journal, 37(8), 1533-1541. http://dx.doi.org/10.1016/ S0014-3057(01)00039-8.

15. Adebiyi, A. P., Adebiyi, A. O., Yamashita, J., Ogawa, T., \& Muramoto, K. (2008). Purification and characterization of antioxidative peptides derived from rice bran protein hydrolysates. European Food Research and Technology, 228(4), 553-563. http://dx.doi.org/10.1007/s00217-008-0962-3.

16. Jerez, A., Partal, P., Martinez, I., Gallegos, C., \& Guerrero, A. (2007). Protein-based bioplastics: effect of thermo-mechanical processing. Rheologica Acta, 46(5), 711-720. http://dx.doi. org/10.1007/s00397-007-0165-z.

17. International Organization for Standardization - ISO. (2012). ISO 527-2: plastics: determination of tensile properties: part 2: test conditions for moulding and extrusion plastics. Geneva: ISO. Retrieved in 26 May 2016, from http://www. iso.org/iso/iso_catalogue/catalogue_tc/catalogue_detail. htm?csnumber $=56046$

18. American Society for Testing and Materials-ASTM. (2001). ASTM D-571: standard test method for water absorption of plastics. West Conshohocken: ASTM. http://dx.doi.org/10.1520/ A0570 A0570M-98.

19. Felix, M., Romero, A., Martín-Alfonso, J. E., \& Guerrero, A. (2015). Development of crayfish protein-PCL biocomposite material processed by injection moulding. Composites. Part B, Engineering, 78, 291-297. http://dx.doi.org/10.1016/j. compositesb.2015.03.057.

20. Rombouts, I., Lagrain, B., Brunnbauer, M., Koehler, P., Brijs, K., \& Delcour, J. A. (2011). Identification of Isopeptide Bonds in Heat-Treated Wheat Gluten Peptides. Journal of Agricultural and Food Chemistry, 59(4), 1236-1243. PMid:21235244. http:// dx.doi.org/10.1021/jf103579u.

21. Schmid, M., Müller, K., Sängerlaub, S., Stäbler, A., Starck, V., Ecker, F., \& Noller, K. (2014). Mechanical and barrier properties of thermoplastic whey protein isolate/ethylene vinyl acetate blends. Journal of Applied Polymer Science, 131(23), n/a. http://dx.doi.org/10.1002/app.41172.

22. Tummala, P., Liu, W., Drzal, L. T., Mohanty, A. K., \& Misra, M. (2006). Influence of Plasticiczers on Thermal and Mechanical Properties and Morphology of Soy-Based Bioplastics. Industrial \& Engineering Chemistry Research, 45(22), 7491-7496. http:// dx.doi.org/10.1021/ie0604391.

Received: May 26, 2016

Revised: July 21, 2016

Accepted: Aug. 03, 2016 